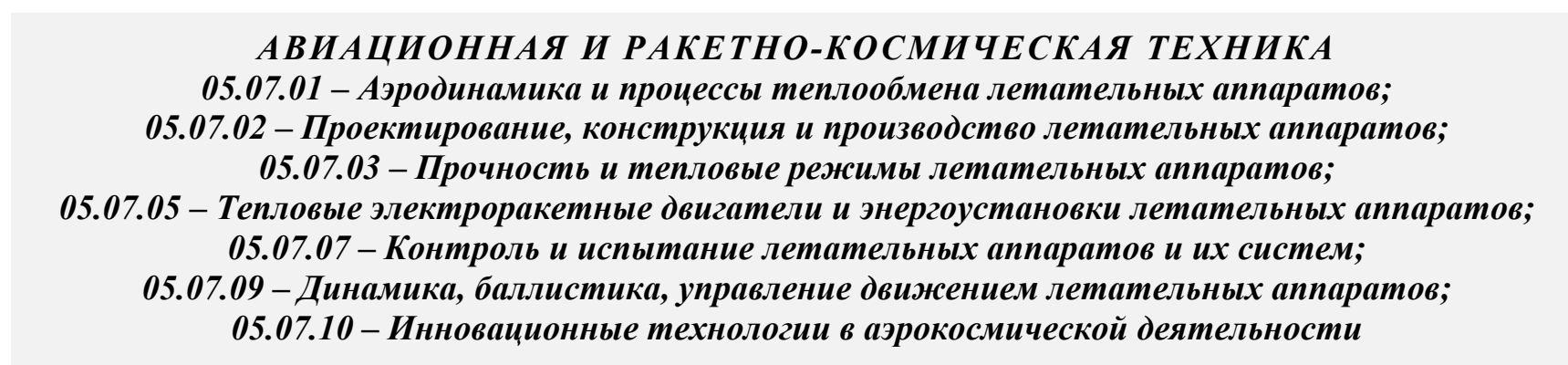

УДК 629.7.05:004.032.2

DOI: $10.26467 / 2079-0619-2020-23-6-84-100$

\title{
SYSTEM BASED APPROACH TO THE DESIGN OF TENSION SENSING ELEMENT MADE OF MODIFIED DIAMOND
}

\author{
S.V. DIANOV ${ }^{1}$, V.M. NOVICHKOV ${ }^{2}$ \\ ${ }^{1}$ Moscow State Technical University of Civil Aviation, Moscow, Russia \\ ${ }^{2}$ Moscow Aviation Institute (National Research University), Moscow, Russia
}

\begin{abstract}
Modern and perspective tasks of robotics with control from artificial intelligence systems require the use of small-sized measuring devices. In this case, the intensively developed quantum sensors and quantum computers have a bright prospect. Their main advantage is the ability to successfully process the data of random processes with decomposition of complex functions into simple multipliers, as well as their small size and the ability to transmit data over long distances without wires. Data transmitted over quantum communication lines cannot be copied or intercepted, which is very useful for remote control of complex technical systems. Based on the results of the analysis of probabilistic noisy data quantum computer is able to quickly develop an assessment of the technical condition of the complex system. At the same time, there is no need to go through all the possible solutions to the evaluation problem with a huge amount of input data, some of which can sometimes be undefined. The main problem in the research of quantum processes is that researchers study the processes occurring in materials, but they do not indicate the ways in which quantum sensors and quantum computers are used in practical applications. This article explains how to form a measuring transformer that will be compatible with a quantum computer. The main objective of the study was to bring the results of basic research in the field of quantum computing closer to their application in applied tasks. It is shown how quantum processes can be shifted to the field of technical measurements of physical quantities used in complex systems. In the process of obtaining the results of the study, the hypothetical deductive method and the method of ascent from the abstract to the concrete within the framework of a systematic approach to the development of elements of technical systems were used. The result is a description of the processes of designing of tension sensing element made of modified diamond. The main findings of the study include the fact that quantum sensors implemented in the form of a modified diamond crystal are well described by the theory of measuring transducers with frequency output and can be used to get data about the state of an object.
\end{abstract}

Key words: sensing element, NV-center, quantum sensor, vibration sensor, measuring channel, converter with frequency output.

\section{INTRODUCTION}

There are many requirements for modern complex technical systems. Robotic units with artificial intelligence are supposed to be a control center of such systems at the time when input data must be holistic and provide comprehensive information from all parts of the system. The control algorithms need adequate information about current state of systems for producing diagnosis of possible failures and malfunctions. Failures and malfunctions are the sign that characterizes ability of the system to carry out its purpose. The malfunctions that were missed can lead to the problems in control algorithms which in turn could result in loss of the object of control. Miniaturization by means of nanotechnologies can help to improve reliability.

For the reliability and accuracy of practical applications of complex technical systems must contain more and more sensors and transducers. The quantity of the sensors and transducers sometimes 
reach hundreds of items. In this case the dimensions and mass of sensors would increase unacceptably for perspective systems if being produced by using existing technologies. Implementation of achievements of nanotechnology and artificial intelligence will help to reach necessary parameters. Therefore, it would be good to use sensors with quantum primary converters. Quantum technologies implements in sensor small size, reliability because of absence of coupled moving parts and possibility of artificial intelligence implementation because of basic feature of uncertainty in quantum states.

For example, one of realizations of the system can be used for diagnostic purposes. Then parameters of stochastic processes would be the input data for the diagnostic algorithms in case of implementation of a large number of sensors in the system. It is a problem for conventional computers. It reflects in solution of the task of factorization of complicated functions, for example. It is a challenge for quantum computers. The advantage of quantum computers is their possible ability to make fast estimation of the future condition of complex technical systems in case where the numerical methods do not apply. Sometimes any input data can be lost because of external influencing actions on sensors and could fail them. Conventional methods of estimation of condition of technical systems in such a situation are not going to operate properly.

Quantum computers are based on qubits exceed in some fields of application any modern conventional supercomputers [1]. These fields are the analysis of big data sets, cryptography, drug development, riddle of superconductivity research, problems of reliability. Moreover, quantum computers are able to accomplish the task of data teleportation. As for hardware the IBM company announced that the real 1000 qubit quantum computer system is to be built in 2023. The Google's 53 qubit quantum computer is used now and Google has a plan to create a million-qubit structure in 10 years [2]. Nowadays new quantum computer algorithms which allow to speed up calculations and unravel a lot of scientific puzzles are under elaboration. For example, the new algorithm for quantum computer which allows to get over the quantum decoherence problem has been developed and tested. It is Variational Fast Forwarding algorithm that has been created by Los Alamos researchers [1].

Features of quantum computers and quantum algorithms presuppose the existence of ability to estimate condition of complex technical systems by means of analyzing stochastic noisy data. The advantage of quantum computers is the absence of necessity for sorting through all possible options of solutions for the task of the estimation problem that has a huge amount of an input data.

Procedure of calculating measuring transducer is offered in this article. The transducer is specially created on the diamond plate with nitrogen-vacancy (NV) center. This center appears in diamond when one carbon $(\mathrm{C})$ atom in crystal lattice of the diamond plate is replaced by a nitrogen $(\mathrm{N})$ atom, and the adjacent carbon atom is removed from the diamond's crystal lattice creating the vacancy (V). The NV center has superb spin coherence and optical properties that make it one of the most promising to implement quantum sensing and quantum computing in practice.

Thus, the NV center can be used as a sensing element for a loadcell. The loadcell could be applied in diagnosis the technical condition of the airframe parts, parts of fuel systems, oil systems, hydraulic systems, pressurization systems, and other systems that work under pressure or tension.

\section{METHOD AND METHODOLOGY OF THE RESEARCH}

We offer to take results of conventional vibration sensors research [3] in order to make smooth transition to the quantum technology. We applied hypothetical-deductive method to this end. Results of the research of the diamond cantilever with NV center were classified according to the classic theory of measurement sensors. The way of developing the measuring converter (sensor or the loadcell in this case) from a diamond plate with NV center was offered as the result of the research. The sensor should input data into a quantum computer. In future, it can be the part of a diagnosis system. 


\section{RESULTS OF THE RESEARCH}

We offer the structure and designing project of measurement channel for a quantum diagnostic computer (computer that is used for diagnosis). The measurement channel is a part of a measurement system that produces one explicit function. It transforms the input measurable value to an analogue signal to the output. The output analogue signal is a function of input parameter that should be measured.

Parameters that can be under control are pressure, strength, and displacement. Moreover, it could be any other parameter that can influence the natural frequency of a diamond plate with NV center.

The dimensions and shape of the diamond plate with an NV center depends on the measurement range of the parameter which is measured or tested. The parameter is the indicator of the state of the tested system. The diamond plate with NV center is both sensor and transducer. They are two in one. It transforms input parameter to photon (or phonon) to the output that will be input value for the quantum diagnostic computer.

We offer to use the diamond plate with NV center as a main part of a measuring channel for the quantum diagnostic computer. Parameters of such a quantum sensor can be calculated by means of the existing theory of measuring transducers with the frequency output. Modern complex technical systems produce a large amount of stochastic data that describes their present and future state. Good technique of such data processing is a quantum computer.

We believe that the diamond plate with NV center virtually consists of two parts. The first one is a diamond plate. It serves as resonator which characteristics can be described by the existing theory of vibration sensors [3]. The second part is the NV center in the modified diamond plate. The NV center serves as a subsequent transducer. Diamond with the NV center is a diamond with broken lattice but it does not influence the mechanical properties particularly the natural frequency of the plate. It allows uniting two transducers in one: the primary (sensing element) and the subsequent (NV center).

The sensor that consists of the resonator and transducer must be vibrated by a special excitation system of vibration. Parameters of the system is possible to calculate. The diamond plate with NV center can produce data for a quantum computer while it vibrates: it generates photons (or phonons) that could be accepted for measuring [4-10].

This approach to new sensor design allows us to use a new type of measuring channel in technical systems. This way organizes physical processes in the diamond and around it. As a result, sensors of the new type are many times smaller than sensors of the conventional types. At the same time, the sensors of the new type can input data directly into the quantum computer system without any additional means such as transformers, transformations or processing. This new type of sensors can also input data to quantum computers by using its photon (or phonon) radiation feature by means of different types of detectors. For example, it can be: a geometric phase magnetometry technique, a microwave-assisted spectroscopy technique, a hyperpolarization-enhanced NMR spectroscopy technique, spin readout techniques $[5-7,11-20]$.

\section{MEASURING CHANNEL FORMATION}

The distinctive feature of quantum computer is the inner structure that complies with tasks that the computer is supposed to solve. Moreover, because of this, an algorithm of transforming of input data to output data could not be changed during the operation. It increases the reliability and decreases the universality. Therefore, a structure of the diagnosis quantum computer should be depended on a diagnosed technical system. The diagnosis quantum computer is the device that use quantum superposition and quantum entangle for data transducing and further transmission for diagnosis purposes. The main goal of the creation the diagnosis quantum computer is ability to autoexecute procedures of technical systems condition estimations for maintenance operations scheduling. Advantages of the quantum transformers allow to improve the assessment of complex technical systems since it can process 
big stochastic data. Diagnostic parameters could determine the structure of diagnosis quantum computer.

The sensing element is the main part of the sensor and in such case characteristics of sensing element are very important. It is impossible to achieve acceptable accuracy of the measuring parameters without appropriate accuracy of the sensor. In addition, external and internal interferences have to be taken into consideration because their disturbing influence should be reduced. It is also important as calculation of characteristics of the sensing element.

The main idea of the work is to show how to use the published results of quantum technologies in practical engineering activity [21 - 25].

Results of research [26-28] allow to produce the loadcell made of diamond with the NV center. The sensing element with the loadcell should sense physical parameters that are needed for diagnosis purposes of technical systems. In a former research [29] the same element was offered as an elementary computing unit for a quantum computer. The unit was named q-bit and it is made of a diamond with the NV center, i.e. of a diamond with artificially changed atomic lattice. One atom of Carbon $\left({ }^{13} \mathrm{C}\right)$ in the diamonds atom structure was replaced by one atom of Nitrogen $(\mathrm{N})$. Another adjacent atom of Carbon was removed and its space became empty. This was named vacancy (V). The whole atomic structure was named as the NV center. The NV center has an axis. Projection of the electron spin on the axis serves as a q-bit. According to the conventional theory of vibrating sensors we call the NV center as sensing element. According to the results of the research [26] the NV center can respond to frequency changes of the diamond plate vibration. This feature allows to create quantum sensors from diamond plates.

Unlike binary number system, when bits can only have states "0" and "1", q-bits (quantum bits), in addition to these two states, can have any value in the range from 0 to 1 . This is determined by the electron spin feature, when it can have any direction in space. This q-bit feature is taken into consideration when forming measurement channel.

The measuring channel is formed to get information from environment via modified diamond that gets fluorescent feature. The feature is the result NV center behavior under external magnetic field $B$. Q-bit information can be stored in the NV center by different energy levels as it is shown by Figure 1 [29]. This energy levels of the NV center electron spin were chosen as q-bit where readout could be performed as optical transition of the NV center.

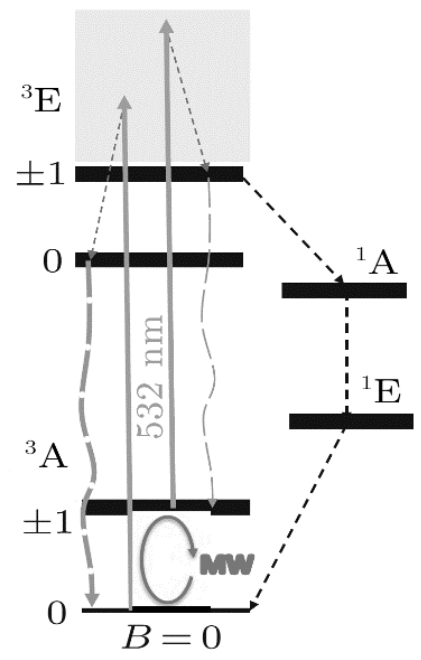

Fig. 1. Energy levels and optical transitions of the NV electron spin

Fluorescence appears under resonant microwave (MW) pulses. Green polarize laser (532 nm) helps the descending dashed lines to appear. It illustrates the fluorescence intensity. Therefore, the spin states can be polarized with green laser and readout by fluorescence intensity. 
As it is shown in Figure 1, energy level of negatively charged NV center (spin-1 system) has ground states of an ${ }^{3} \mathrm{~A}$ spin triplet, with a zerofield splitting between 0 and \pm 1 sub-levels. The degeneracy between \pm 1 states can be lifted by an external magnetic field $B$, then either one of them together with 0 state can form a well-defined two-level system, which is the physical implementation of a q-bit. The quantum state of this spin q-bit can be manipulated with resonant MW pulses [29].

The polarization and readout of this q-bit is realized by exploiting the spin-dependent optical transitions of NV centers. As shown in Figure 1, the energy gap between the ground ${ }^{3} \mathrm{~A}$ state and the excited ${ }^{3} \mathrm{E}$ state is $1.945 \mathrm{eV}(637 \mathrm{~nm})$. A laser pulse with photon energy larger than $1.945 \mathrm{eV}$ (e.g., 532-nm green laser) can excite the electron spin to its excited states, then there is a difference in choosing the paths back to the ground states: the states \pm 1 are more likely to be trapped by the ${ }^{1} \mathrm{~A}$ singlet and have less fluorescence compared to the state 0 , thus spin state information can be extracted from the fluorescence intensity. Meanwhile, populations in the ${ }^{1} \mathrm{~A}$ singlet have a large probability of jumping back to ground state 0 , so the off-resonant laser excitation is also polarized [29]. In order to form a proper measurement channel, we are interested in the fluorescence feature of the NV center.

Optically detected magnetic resonance (ODMR) spectrum of an NV center is illustrated by Figure 2 [29].

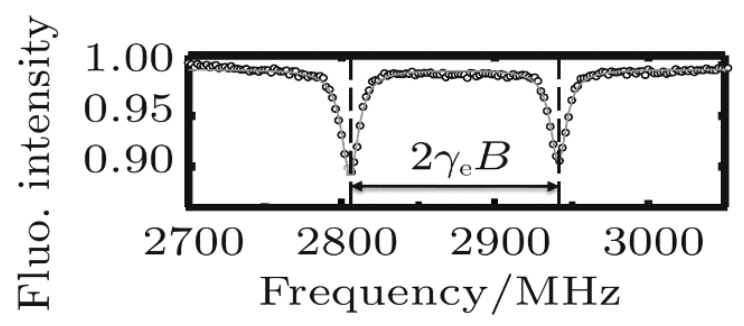

Fig. 2. Optical detected magnetic resonance spectrum of an NV center

The ODMR phenomenon is a result of spin-lattice relaxation which defines the energy transfer between the NV center and its environment. We chose this feature of fluorescence of NV center registered via ODMR as an informative parameter of the sensor in our research.

This NV center is the subsequent element of the measuring channel that is designed by our approach. Therefore, the primary (sensing) element is the diamond plate that is used according to the rules of conventional theory of vibrating sensors. We assume the NV center as secondary transducer. The sensing element should be vibrated by a special excitation of oscillations system in order to make NV center operate. For example, quantum properties of the NV center in the experiments [26] are manipulated by microwave magnetic fields generated by a nearby antenna. The NV center has to be initialized by green laser light for the functioning. So, the sensing element has two parts: a diamond plate and NV center in it.

The measuring channel for a quantum computer system also should consist of two parts. The first one is a diamond plate with the NV center. The second one is a special excitation system. The measuring channel has an analog output signal. The analog signal can be detected by microwave spectroscopy of phonon-dressed states.

\section{SENSOR SCHEME SELECTION}

There are two ways of achieving output information from the measuring channel.

The first one is the following: the eigenstate " 0 " has more fluorescence intensity then eigenstate "1". It was proved by confocal optical microscope detection [16 - 18]. The speed of information recording for the unit is for about $10^{-9} \mathrm{sec}$. Data were read by estimating the fluorescence intensity. The common problem of quantum units is their instability. In that unit data can be stored for about a few seconds. It's a pretty good result. Data could be inputted directly into a quantum computer by photons. 
The second way was worked out as the result of research that was made in the Swiss Nanoscience Institute and University of Basel [26]. In this case, the resonator is a diamond cantilever with the $\mathrm{NV}$ center and there is the opportunity to manipulate quantum properties by the mechanical strain that arises in the diamond cantilever. The process takes place at room temperature. Quantum properties are coherent oscillations of an embedded NV center spin. Sensitive elements performance in this case is about $10^{-7} \mathrm{sec}$.

In the other research [28] it was offered to make the resonator with the NV center as a unit of quantum computer systems. It allows to process big stochastic data of the mechanical strain in board systems. It allows to exclude the data transmission path and to process data immediately. Implementation of this result in technical diagnostic means will lead to decrease of energy consumption, quantity of wires, and noise in data.

Both approaches can be described by well-known classical theory of vibrating sensors. Vibration properties of diamond plate, which is used as a quantum sensor, were studied earlier $[3,30]$.

So, in order to get information about diagnosing system it is necessary to change in time the rigidity of a diamond plate with NV center. Changing the rigidity of the loadcell leads to changing its natural frequency of vibrations. The natural frequency influences to quantum properties of the NV center. Therefore, NV center produces photons or phonons. Photons or phonons intensity can be directly input as data into a quantum computer system as it was described before. The quantum measuring channel has an advantage over conventional technologies because of its structural (not engineering) simplicity, noise immunity as in digital systems, universality of analog systems and accuracy.

The sensitive element made of modified diamond should be theoretically divided into two parts to get better results in vibration sensor engineering. The sensitive element within the framework of classical theory of vibrating converters is mechanical. The mode of its functioning is frequency dependence resonator. There are two types of vibrating plate operation: free oscillation (see Figure 3) and self-oscillation (see Figure 4).The figures illustrates the way that the resonator can operate.

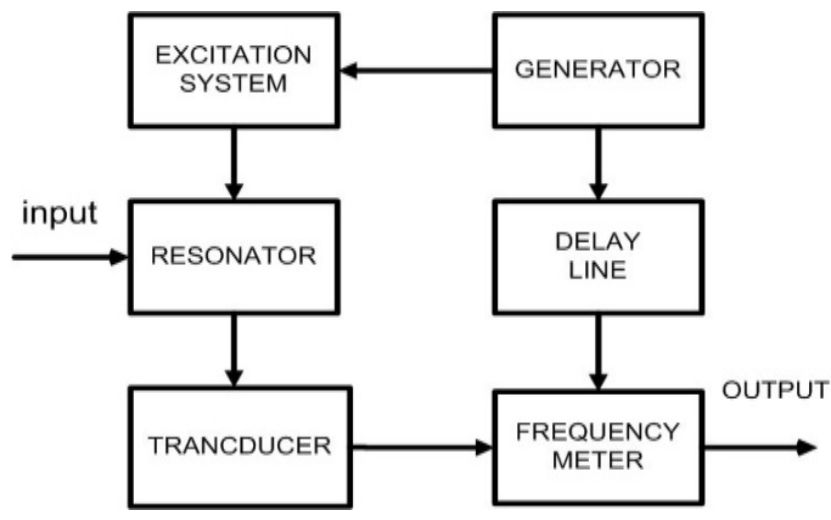

Fig. 3. Functional diagram of the sensor operation in free oscillation mode

The operation principle of the sensitive element is the ability to change its natural frequency under influence of the parameter that is measured. Free oscillation condition is actuated by the exciting vibration system. The resonator begins to oscillate at free vibrations frequency $\omega_{\mathrm{c}}$ just after the starting pulse action. Vibration frequency can be calculated as

$$
\omega_{\mathrm{c}}=\omega_{m} \sqrt{1-d^{2}}
$$

here $d$-damped vibrations factor, $\omega_{m}$ - natural frequency of the diamond plate.

$\omega_{\mathrm{c}}$ is the information parameter which depends on mechanical strain in the loadcell. 
Figure 4 illustrates the case of the resonator operation at the self-oscillation condition. The regenerative feedback is needed for self-excitation and sustainable work of the sensing unit. A piezoelement can be used to this end. For the case $d<<1$ the frequency of oscillations of the resonator is near natural frequency $\omega_{m}$. It is possible to estimate the mechanical parameter that is measured by means of measuring of the frequency of oscillations.

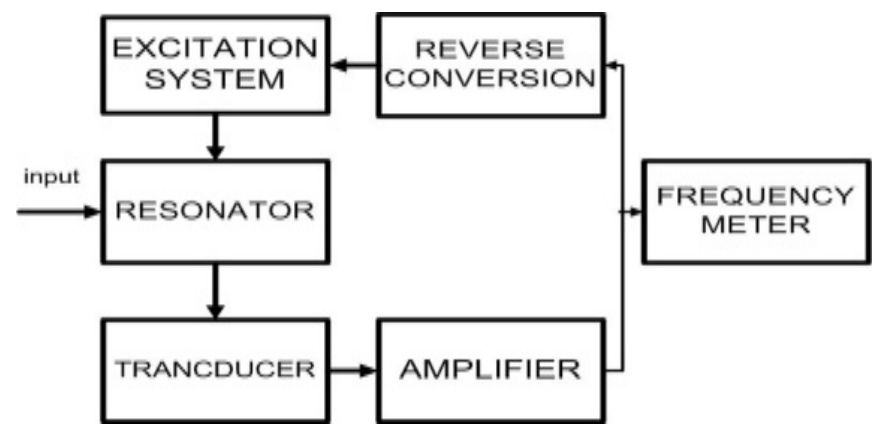

Fig.4. Functional diagram of the sensor operation in self-oscillation mode

The resonator is the main part of the whole measuring channel. There are 8 main types of resonators [3]. These resonators are pendulum, balance-spring, stringed resonator, V-shape plate, cylinder shell, tuning fork, quartz resonator and magnetostrictive rod.

Among them the most convenient for creating a measuring element of a modified diamond are stringed resonator, V-shape plate (see Figure 5), where $\mathrm{X}$ is a measured parameter.
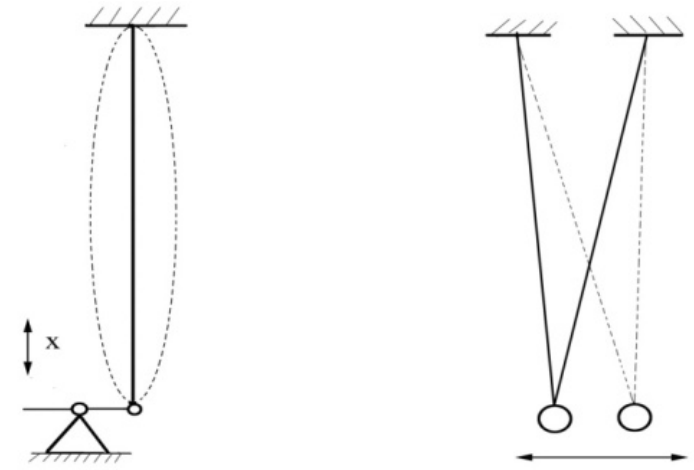

Fig. 5. Types of resonators for measuring element

A cantilever is a combination of stringed resonator and V-shape plate. Usually the oscillations of cantilever contain a lot of parasitic oscillations. The diamond plate is an oscillation system that has a few degrees of a freedom and respectively a few resonance frequencies.

The flexural rigidity $k$ and mass ${ }_{m}$ determine the natural frequency of the resonator. For example for the stringed sensor the natural frequency calculated upon the formula

$$
f_{0}=\frac{1}{2 \pi} \cdot \sqrt{\frac{k}{m}}
$$

This task earlier was solved for other traditional applications and can be solved for this case. 


\section{DESCRIPTION OF THE INFORMATIVE PARAMETER OF THE QUANTUM SENSING ELEMENT}

The diamond plate with NV center is an oscillatory system with spatial parameters. Its natural frequency is the function of the distributed mass and elasticity. When the cantilever made of modified diamond oscillates there will appear an energy gap (see Figure 6, [26]). The energy gap in the electron spin resonance of the NV center has been observed in the research [26]. It was shown that there is a high Q-factor which is about $5 \cdot 10^{7}$ for diamond plate.
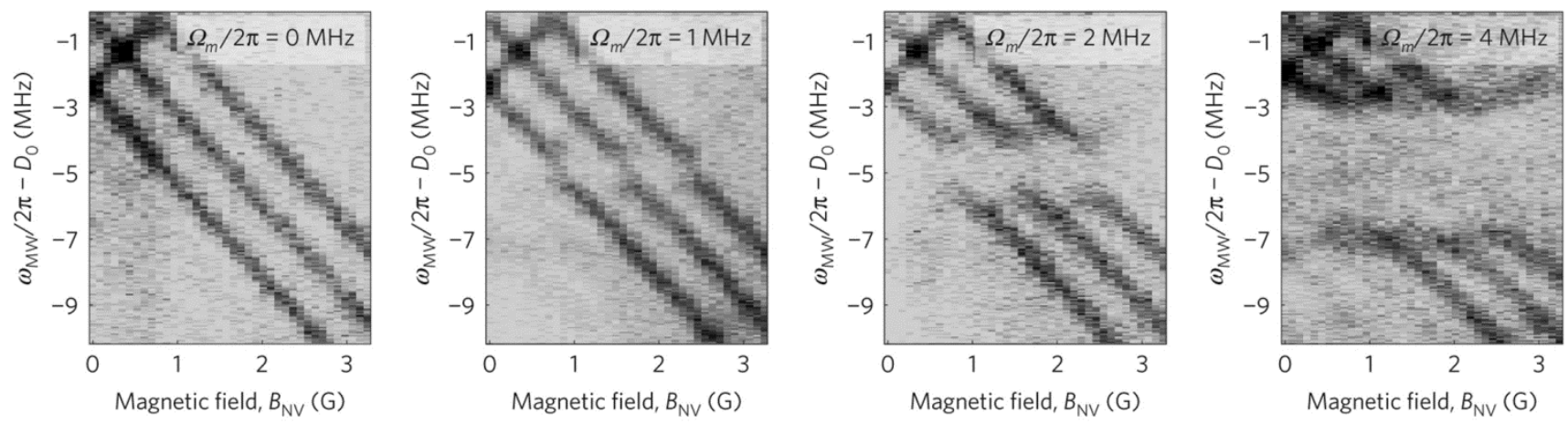

Fig. 6. Changing energy gap in the electron spin resonance of the NV center

The energy gap is the property of a diamond plate with the NV center and the gap depends on the diamond plate oscillations frequency.

We offer to use this energy gap as the output data in the sensor. We assume this because the result of the research [26] shows that strain fields allow to manipulate the electron spin of the NV center in the strong-driving regime. In that experiment the diamond plate with $\mathrm{NV}$ center has been driven by the excitation system which runs the free vibrations. The piezo-element was used to this end.

It was shown [26] that the energy gap can be observed by microwave probe at resonance frequency. The gap depends on the natural frequency of the plate and Rabi frequency $\Omega_{m}$. We believe that since flexural rigidity of the plate is under influence of the parameter which is measured and for its part directly affects the natural frequency of the diamond plate. Therefore, emergence of the energy gap could be output data of the loadcell.

\section{EVALUATION OF THE SENSOR PARAMETERS}

The natural frequency of the sensor depends on several factors. The most important are shape, sizes, and fastening type. The shape and sizes of the sensitive element can be calculated upon known formulas. The manner of attaching the plate is very important. There is developed [30] technique of calculating diamond plates with shape, sizes, and natural frequency which we need.

$$
\begin{gathered}
\mathrm{f}_{\mathrm{m}}=\mathrm{F} \cdot \mathrm{C}, \\
\mathrm{F}=\frac{K\left(1.17-\frac{h}{d}\right) \frac{h}{d^{2}}}{\sqrt{1-\mu^{2}}},
\end{gathered}
$$

here $f_{m}$ - natural frequency, $C$ - velocity of propagation of the elastic wave in infinite waveguide arm, for diamond is 18300 meter per second, $F$ - shape factor, $h$ - height of the plate, $d$-diameter of the inscribed circle, $\mu$ - Poisson's ratio for diamond is $0.07, K$ - factor which depend on the shape and the manner of attaching (available from an experimental data). 
The rectangular and round shape of the sensor are more convenient for calculating and producing. There are few $K$ factors that were calculated.

For rectangular plate $K=0.603$ if plate was fastened by the corner, $K=0.879$ if plate was fastened by the edge, $K=1.022$ if plate was fastened by the middle [30].

For round plate $K=0.954$ if plate was fastened by the edge, $K=1.298$ if plate was fastened by the middle [30].

The process of engineering of the sensitive element made of modified diamond plate, which is designed for the required frequency range, consists of the following steps:

1) the first step is producing the NV center in a diamond plate;

2) the second step is calculating and manufacturing the required shape plate, and fastening it appropriately;

3) the exciting vibration system for the diamond plate must be build;

4) the regenerative feedback which is needed for self-excitation and sustained work of the sensing unit. The piezo-element can be used to this end.

The resonator is the mechanical plate. Therefore, the static characteristic or the static response the output parameter from the input parameter could be defined by the formula

$$
f=f_{m} \sqrt{1+k x}
$$

here $f_{m}$ - natural frequency of the resonator $(\mathrm{Hz}), k$ - coefficient which depends on the shape, sizes, temperature of manufacturing and using etc., all of this could be controlled during the manufacturing and operation the sensor. The output parameter is $f$. The input parameter is flexural rigidity ${ }_{x}$ of diamond plate that depends on the shape. Elastic expansion arises subject to mechanical loading in the diamond plate. Its flexural rigidity depends on the elastic modulus or the Young's modulus $E$. The Young's modulus is ratio of small deformation strain. $C$ - velocity of propagation of the elastic wave in infinite waveguide arm depends on the Young's modulus

$$
\mathrm{C}=\sqrt{\frac{E}{\rho}}
$$

here $\rho$-density of the material. The natural frequency of the diamond plate $f_{m}$ is under $\rho$ influence.

The quadratic approximation is applied to define the real static characteristic $\left(f_{m}\right.$ and $\left.k\right)$ of the resonator from the available experimental data

$$
x=b f^{2}-a,
$$

here $a=k^{-1} ; \quad b=\frac{1}{f_{m}^{2} k}=\frac{a}{f_{m}^{2}}$.

The target function could be minimized by the selection the parameters $f_{m}$ and $k$

$$
J=\sum_{i=1}^{n}\left[x_{i}-\left(b f_{i}^{2}-a\right)\right]^{2},
$$

$n$-the number of the measurement results of the output parameter $x$.

$f_{i}$ - the frequency of the $x_{i}$ output parameter which depends on the width of the energy gap of the ESP (electron spin resonance). 
Estimates of $\widehat{f_{m}}$ and $\hat{k}$ which minimize the target function could be calculated upon the formulas

$$
f_{m}^{2}=\frac{\sum_{i=1}^{n} f_{i}^{2} \sum_{i=1}^{n} x_{i} f_{i}^{2}-\sum_{i=1}^{n} f_{i}^{4} \sum_{i=1}^{n} x_{i}}{n \sum_{i=1}^{n} x_{i} f_{i}^{2}-\sum_{i=1}^{n} x_{i} \sum_{i=1}^{n} f_{i}^{2}} ; \quad k=\frac{n \sum_{i=1}^{n} f_{i}^{4}-\left(\sum_{i=1}^{n} f_{i}^{2}\right)^{2}}{\sum_{i=1}^{n} f_{i}^{2} \sum_{i=1}^{n} x_{i} f_{i}^{2}-\sum_{i=1}^{n} f_{i}^{4} \sum_{i=1}^{n} x_{i}} .
$$

There are two most perspective ways of putting the loadcell into practice. The way of calculating the natural frequency of the diamond plate $f_{m}$ for both was represented in the study [31]. One of them is the fastening as the strut with vertical axial load applied. The formula for calculating for this case is

$$
f_{m}=\sqrt{\frac{E I\left(\frac{\pi}{l}\right)^{2}-S}{m l}},
$$

here $I$ - second moment of area, $E$ - Young's modulus or elastic modulus, $l$ - length, $m$ - mass, $S-$ vertical axial load.

The second one is more common. The plate in this case has two free edges and fixed two other edges (see Figure 7).

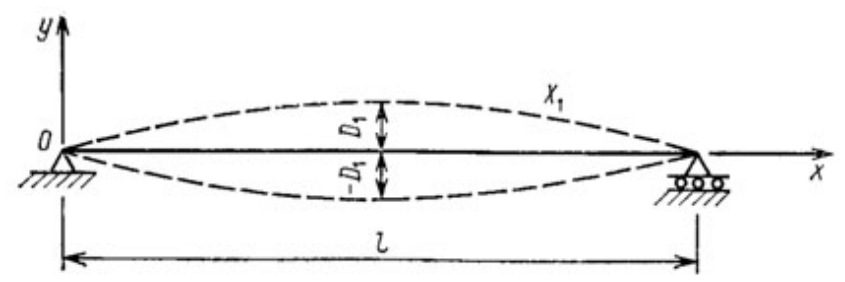

Fig. 7. Oscillation diagram of a plate with two clamped ends (fixed and movable)

The shape of curves which describe the deflections of the beam can be calculated using the formula $\mathrm{X}_{\mathrm{i}}=\mathrm{D}_{\mathrm{i}} \sin \left(\frac{i \pi x}{l}\right)$, here $i$ - the serial number of the harmonic. Figure 8 [31] represents different variants of sine wave vibrations of the beam.

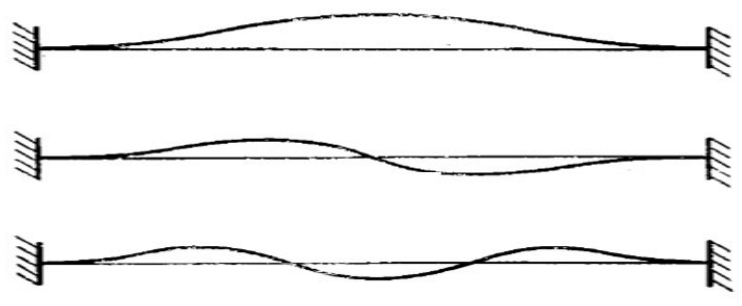

Fig. 8. The variants of sine wave vibrations of the beam

The method of calculating the sensor consists in following. The first step is to estimate appropriate dimensions. We chose the rectangular cross section beam $\mathrm{a} \times \mathrm{b}$ with $\mathrm{a}=1 \cdot 10^{-4} \mathrm{~m}, \mathrm{~b}=5 \cdot 10^{-4} \mathrm{~m}$ 
respectively. Second moment of area in this case $I=\frac{a * b^{3}}{12}$. The formula [31] is used to calculate the lowest, or fundamental, natural frequency of a free beam which is simply supported at each end according to

$$
\omega=\sqrt{\frac{48 E I g}{m l^{3}}}=\sqrt{\frac{48 E I g}{v \rho l^{3}}}
$$

here $E=1.2 \cdot 10^{12} \mathrm{~Pa}$, Young's modulus of diamond; $\mathrm{g} \approx 9.81 \mathrm{~m} / \mathrm{s}^{2}$, acceleration of gravity; $l$ - length, $m$ - mass, $\rho=3.51 \cdot 10^{3} \mathrm{~kg} / \mathrm{m}^{3}$ specific density of diamond.

The frequency range where the energy gap was detected is

from $\frac{\omega_{1}}{2 \pi}=1 \cdot 10^{6} \mathrm{~Hz}$ to $\frac{\omega_{2}}{2 \pi}=4 \cdot 10^{6} \mathrm{~Hz}$.

Thus, $l$ for this case is from $2.2 \cdot 10^{-3} \mathrm{~m}$ to $4.3 \cdot 10^{-3} \mathrm{~m}$.

The next step is calculating the exact length of the loadcell for the right measurement range of strength. In accordance with the classical theory [31], the beam which is fastened at each end, changes its natural frequency under stress.

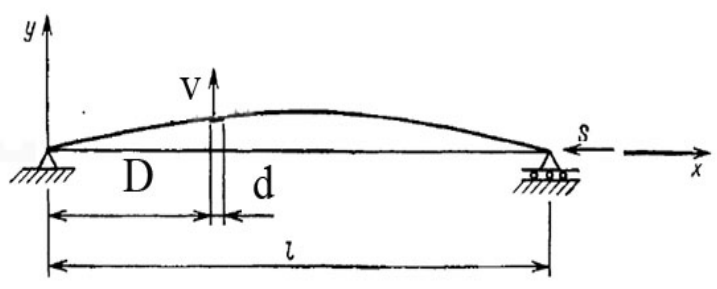

a) compression

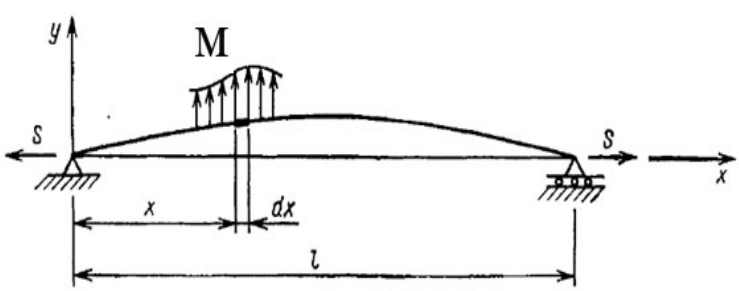

b) tension

Fig. 9. Forces acting on the plate

The natural frequency of the beam reduces under compression and increases under tensile (see Figure 9). The differential equation for the curve of deflection of the beam under tensile force is

$$
\mathrm{EI} \frac{d^{2} y}{d x^{2}}=\mathrm{M}+\mathrm{Sy}
$$

where $M$ is the moment of deflection.

The solution of differential equation is $Y=X(A \cdot \cos (\omega t)+B \cdot \sin (\omega t))$, where $X$ is the orthogonal function, $Y$ is the movement; $A_{i}=\frac{2}{l} \int_{0}^{l} f_{1}(x) \sin \frac{i \pi x}{i} d x$, where $f_{1}(x)$-distribution function of the initial cross travel; $B_{i}=\frac{2}{l \omega_{i}} \int_{0}^{l} f_{2}(x) \sin \frac{i \pi x}{i} d x$, where $f_{2}(x)$ - distribution function of the initial velocities; natural frequency $\omega$ of the beam under compression stress is $\omega=\frac{\pi^{2} 4 a}{l^{2}} \sqrt{1-\frac{S l^{2}}{4 E \pi^{2} I}}, a=\sqrt{\frac{E I}{F \rho}}$, were $F$ is cross-sectional area of the beam, $S$ - compressive force.

Thus we calculate the range of measuring force for the sensor which length is $l=2 \cdot 10^{-3} \mathrm{~m}$ and the rectangular cross section beam $a \times b$ with $a=1 \cdot 10^{-4} \mathrm{~m}, b=5 \cdot 10^{-4} \mathrm{~m}$ respectively. The frequency range is of $\frac{\omega_{1}}{2 \pi}=10^{6} \mathrm{~Hz}$ to $\frac{\omega_{2}}{2 \pi}=4 \cdot 10^{6} \mathrm{~Hz}$.

If we assume that $b=\frac{\pi^{2} 4 a}{l^{2}}$ and $=\frac{l^{2}}{4 E \pi^{2} I}$, then $S=\frac{1-\frac{\omega^{2}}{b^{2}}}{c}$. 
Thus for the compression force $S=1.11 \cdot 10^{3} \mathrm{~N}$ the natural frequency is $\frac{\omega_{1}}{2 \pi}=4 \cdot 10^{6} \mathrm{~Hz}$ and for the compression force $S=1.16 \cdot 10^{4} \mathrm{~N}$ the natural frequency is $\frac{\omega_{1}}{2 \pi}=10^{6} \mathrm{~Hz}$.

Sensor, which is resonantly driven at frequency $\omega$ by a piezo-element, should make a strike to the beam in initial time in order to start operating.

On Figure $9 \mathrm{~d}$ is the short part of the beam that has an initial velocity V. In that case $f_{1}(x)=0$ and $\mathrm{f}_{2}(\mathrm{x})=0$ everywhere except $\mathrm{x}=\mathrm{D}, \mathrm{f}_{2}(\mathrm{D})=\mathrm{V}$.

Thus

$\mathrm{A}_{\mathrm{i}}=0 ; \mathrm{B}_{\mathrm{i}}=\frac{2 V d}{l \omega_{i}} \sin \frac{i \pi d}{i}$; here $\mathrm{i}$ is a serial number of the harmonic.

$\mathrm{y}=\frac{2 v d}{l} \sum_{i=1}^{\infty} \frac{1}{\omega_{\mathrm{i}}} \sin \frac{i \pi x}{l} \sin \frac{i \pi D}{l} \sin \omega_{\mathrm{i}} t$, here $t$ is time.

For the piezo-element which was fastened to the middle of the sensor

$\mathrm{D}=\frac{l}{2}$,

The equation for the movement is

$$
\mathrm{y}=\frac{2 v d}{l}\left(\frac{1}{\omega_{1}} \sin \frac{\pi x}{l} \sin \omega_{1} \mathrm{t}-\frac{1}{\omega_{31}} \sin \frac{3 \pi x}{l} \sin \omega_{3} \mathrm{t}+\frac{1}{\omega_{5}} \sin \frac{5 \pi x}{l} \sin \omega_{5} \mathrm{t}-\cdots\right) .
$$

Static characteristic of the loadcell is now hardly predictable in case of fastening the exciting piezo-element on the free end of the beam not to the middle, as it was done during research [26].

\section{CONCLUSION}

The article presents a new approach to the construction of miniature sensors based on quantum technologies. The calculations are given to show the possibility of physical implementation of vibration sensors based on a modified diamond plate.

This is the step-by-step approach to the development of non-demolish diagnosis quantum computer for complex technical systems. The represented approach illustrates the way of new technological level implementation in practice. The approach to the design of tension sensing element made of modified diamond allows us to use the achievement of quantum technologies in the new type of sensors. The authors used the well-known methods of theory of vibration sensors and mechanics of materials to show the way of engineering of quantum sensing element with NV center. The paper describes the loadcell which is the sensor of a new type.

The conventional theory makes the transition to the new technologies smooth and convenient. In this study the definition of the loadcell of new type has been provided. The dimensions of the loadcell of different shape and manner of fastening were calculated and listed in the article. The trouble occurrence was calculated and listed as well.

\section{REFERENCES}

1. Cîrstoiu, C., Holmes, Z. and Iosue, J. (2020). Variational fast forwarding for quantum simulation beyond the coherence time. NPJ Quantum Information, vol. 6, no. 82, p. 10. DOI: https://doi.org/10.1038/s41534-020-00302-0

2. Cho, A. (2020). IBM promises 1000-qubit quantum computer-a milestone-by 2023. Science. 15 September. DOI: https://doi.org/10.1126/science.abe8122 (accessed 19.09.2020).

3. Gorenshtein, I.A. (1976). Gidrostatichnye chastotnyye datchiki pervichnoy informatsii [Hydrostatic frequency sensors of primary information]. Moscow: Mashinostroyeniye, 182 p. (in Russian) 
4. Arai, K., Lee, J., Belthangady, C., Glenn, D.R., Zhang, H. and Walsworth, R.L. (2018). Geometric phase magnetometry using a solid-state spin. Nature Communication 9, Article number: 4996. DOI: https://doi.org/10.1038/s41467-018-07489-z (accessed 08.09.2020).

5. Craik, D.P.L.A., Kehayias, P., Greenspon, A.S. and others. (2018). A microwaveassisted spectroscopy technique for determining charge state in nitrogen-vacancy ensembles in diamond. arXiv.org. Available at: https://arxiv.org/abs/1811.01972v1 (accessed 02.10.2020).

6. Bhallamudi, V. and Hammel, P. (2015). Nanoscale MRI. Nature Nanotechnology 10, pp. 104-106. DOI: https://doi.org/10.1038/nnano.2015.7 (accessed 08.10.2020).

7. Bucher, D.B., Glenn, D.R., Park, H., Lukin, M.D. and Walsworth, R.L. (2018). $H y$ perpolarization-enhanced NMR spectroscopy with femtomole sensitivity using quantum defects in diam. Physical Review X. DOI: 10.1103/PhysRevX.10.021053 (accessed 08.09.2020).

8. Casola, F., van der Sar, T. and Yacoby, A. (2018). Probing condensed matter physics with magnetometry based on nitrogen-vacancy centres in diamond. Nature Review Materials, vol. 3, Article number: 17088. Available at: https://www.nature.com/articles/natrevmats201788 (accessed 08.09.2020).

9. Teeling-Smith, R.M., Jung, Y.W., Scozzaro, N. and others. (2016). Electron paramagnetic resonance of a single nanodiamond attached to an individual biomolecule. Biophysical Journal, vol. 110, issue 9, pp. 2044-2052. DOI: https://doi.org/10.1016/j.bpj.2016.03.022

10. Schloss, J.M., Barry, J.F., Turner, M.J. and Walsworth, R.L. (2018). Simultaneous broadband vector magnetometry using solid-state spins. Physical Review Applied, vol. 10, issue 3, pp. 034-044. DOI: https://doi.org/10.1103/PhysRevApplied.10.034044

11. Hopper, D.A., Shulevitz, H.J. and Bassett, L.C. (2018). Spin readout techniques of the nitrogen-vacancy center in diamond. Micromachines, vol. 9, issue 9, 437. DOI: https://doi.org/10.3390/mi9090437 (accessed 08.09.2020).

12. Fernández-Acebal, P., Rosolio, O., Scheuer, J. and others. (2018). Toward hyperpolarization of oil molecules via single nitrogen vacancy centers in diamond. Nano Lett, vol. 18, no. 3, pp. 1882-1887. DOI: https://doi.org/10.1021/acs.nanolett.7b05175

13. Jaskula, J.-C., Shields, B.J., Bauch, E., Lukin, M.D., Trifonov, A.S. and Walsworth, R.L. (2019). Improved quantum sensing with a single solid-state spin via spin-to-charge conversion. Physical Review Applied, vol. 11, issue 6. DOI: https://doi.org/10.1103/PhysRevApplied.11.064003 (accessed 08.09.2020).

14. Marseglia, L., Saha, K., Ajoy, A. and others. (2018). Bright nanowire single photon source based on siv centers in diamond. Optics Express, vol. 26, issue 1, pp. 80-89. DOI: https://doi.org/10.1364/OE.26.000080_(accessed 08.09.2020).

15. Ohtsu, M. (2012). Dressed photon technology. Nanophotonics, vol. 1, issue 1, pp. 83-97. DOI: https://doi.org/10.1515/nanoph-2011-0001_(accessed 08.09.2020).

16. Jia, W., Shi, Z., Qin, X., Rong, X. and Du, J. (2018). Ultra-broadband coplanar waveguide for optically detected magnetic resonance of nitrogen-vacancy centers in diamond. Review of Scientific Instruments, vol. 89, issue 6. DOI: https://doi.org/10.1063/1.5028335_(accessed 08.09.2020).

17. Wolfe, C.S., Manuilov, S.A., Purser, C.M., Teeling-Smith, R., Dubs, C., Hammel, P.C. and Bhallamudi, V.P. (2016). Spatially resolved detection of complex ferromagnetic dynamics using optically detected nitrogen-vacancy spins. Applied Physics Letters, vol. 108, issue 23. DOI: https://doi.org/10.1063/1.4953108_(accessed 08.09.2020).

18. Tang, H., Ahmed, I., Puttapirat, P. and other. (2018). Investigation of multi-bunching by generating multi-order fluorescence of NV center in diamond. Physical Chemistry Chemical Physics, vol. 20, issue 8, pp. 5721-5725. DOI: https://doi.org/10.1039/C7CP08005K (accessed 08.09.2020).

19. Labanowski, D., Bhallamudi, V.P., Guo, Q., Purser, C.M. and McCullian, B.A. (2018). Voltage-driven, local, and efficient excitation of nitrogen-vacancy centers in diamond. Science Advances, vol. 4, no. 9.6 p. DOI: https://doi.org/10.1126/sciadv.aat6574 (accessed 08.09.2020). 
20. Chrostoski, P., Sadeghpour, H.R. and Santamore, D.H. (2018). Electric noise spectra of a near-surface nitrogen-vacancy center in diamond with a protective layer. Physical Review Applied, vol. 10, issue 6. DOI: https://doi.org/10.1103/PhysRevApplied.10.064056 (accessed 08.09.2020).

21. Murai, T., Makino, T., Kato, H. and other. (2018). Engineering of fermi level by nin diamond junction for control of charge states of NV centers. Applied Physics Letters, vol. 112, issue 11. DOI: https://doi.org/10.1063/1.5010956 (accessed 08.09.2020).

22. Subedi, S.D., Fedorov, V.V., Peppers, J., Martyshkin, D.V., Mirov, S.B., Shao, L. and Loncar, M. (2018). Laser spectroscopy of highly doped NV-centers in diamond. Proceedings SPIE, vol. 10511, Solid State Lasers XXVII: Technology and Devices, 105112D DOI: https://doi.org/10.1117/12.2290705 (accessed 08.09.2020).

23. Sjolander, T.F., Tayler, M.C.D., Kentner, A., Budker, D. and Pines, A. (2017). 13CDecoupled J-coupling spectroscopy using two-dimensional nuclear magnetic resonance at zero-field. The Journal of Physical Chemistry Letters, vol. 8, issue 7, pp. 1512-1516. DOI: https://doi.org/10.1021/acs.jpclett.7b00349 (accessed 08.09.2020).

24. Udvarhelyi, P., Shkolnikov, V.O., Gali, A., Burkard, G. and Pályi, A. (2018). Spinstrain interaction in nitrogen-vacancy centers in diamond. Physical Review B, vol. 98, issue 7, 075201. DOI: https://doi.org/10.1103/PhysRevB.98.075201 (accessed 08.09.2020).

25. Zhang, H., Ku, M.J.H., Casola, F. and others. (2020). Spin-torque oscillation in a magnetic insulator probed by a single-spin sensor. Physical Review B, vol. 102, issue 2, 024404. DOI: https://doi.org/10.1103/PhysRevB.102.024404 (accessed 08.09.2020).

26. Barfuss, A., Teissier, J., Neu, E.A. Nunnenkamp, E.A. and Maletinsky, P. (2015). Strong mechanical driving of a single electron spin. Nature Physics, vol. 11, pp. 820-824. DOI: https://doi.org/10.1038/nphys3411 (accessed 08.09.2020).

27. Delaney, P., Greer, J.C. and Larsson, J.A. (2010). Spin-polarization mechanisms of the nitrogen-vacancy center in diamond. Nano Letters, vol. 10, issue 2, pp. 610-614. DOI: https://doi.org/10.1021/n1903646p (accessed 08.09.2020).

28. Zhu, X., Saito, S., Kemp, A. and other. (2011). Coherent coupling of a superconducting flux qubit to an electron spin ensemble in diamond. Nature, vol. 478, pp. 221-224. DOI: https://doi.org/10.1038/nature10462 (accessed 08.09.2020).

29. Liu, G.-Q. and Pan, X.-Y. (2018). Quantum information processing with nitrogenvacancy centers in diamond. Chinese Physics B, vol. 27, no. 2. DOI: https://doi.org/10.1088/16741056/27/2/020304 (accessed 08.09.2020).

30. Volkov, D.I. and Proskuryakov, S.D. (2016). Ultrasonic method of quality control of the cutting plates from supersolid materials. Izvestiya Samarskogo nauchnogo tsentra Rossiyskoy akademii nauk, vol. 18, no. 1-2, pp. 166-169. (in Russian)

31. Timoshenko, S. (1937). Vibration Problems in Engineering. D.N.Y., Van Nostrand Company, Inc., 470 p. Available at: https://archive.org/details/vibrationproblem031611 mbp/mode/2up (accessed 02.10.2020)

\section{INFORMATION ABOUT THE AUTHORS}

Sergey V. Dianov, Candidate of Technical Sciences, Associate Professor of Moscow State Technical University of Civil Aviation, tehnomat@ya.ru

Vadim M. Novichkov, Candidate of Technical Sciences, Associate Professor, Associate Professor of Moscow Aviation Institute (National Research University), v13217@ya.ru 


\title{
СИСТЕМНЫЙ ПОДХОД К РАЗРАБОТКЕ ДАТЧИКА МЕХАНИЧЕСКОЙ НАГРУЗКИ ИЗ МОДИФИЦИРОВАННОГО АЛМАЗА
}

\author{
С.В. Дианов ${ }^{1}$, В.М. Новичков ${ }^{2}$ \\ ${ }^{1}$ Московский государственный технический университет гражданской авиации, \\ г. Москва, Россия \\ ${ }^{2}$ Московский авиационный институт (национальный исследовательский \\ университет), г. Москва, Россия
}

\begin{abstract}
Решение современных и перспективных задач, решаемых робототехническими устройствами, которые управляются с помощью искусственного интеллекта, требует применения малогабаритных измерительных приборов. В этом случае хорошую перспективу имеют интенсивно разрабатываемые квантовые датчики и квантовые компьютеры. Главным преимуществом квантовых технологий является возможность обработки данных случайных процессов с разложением сложных функций на простые множители при малом размере квантовых устройств и возможности передачи данных на большие расстояния без проводов. Особенность состоит в том, что данные, передаваемые по квантовым линиям связи, не могут быть скопированы или перехвачены, что очень полезно для дистанционного управления сложными техническими системами. Квантовый компьютер способен успешно обрабатывать большой объём вероятностных зашумлённых данных так, что это его свойство может быть полезно для быстрого получения оценки технического состояния сложной системы. Это связано с тем, что пропадает необходимость перебирать все возможные решения задачи оценки с огромным объёмом входных данных, некоторые из которых могут быть явно не определены. Основная проблема в исследовании квантовых процессов заключается в том, что исследователи изучают процессы, происходящие в материалах, но они не указывают способы, которыми квантовые датчики могут быть применены в инженерной практике. В данной статье демонстрируется, как сформировать измерительный преобразователь, основанный на квантовых технологиях и который совместим как с квантовым, так и с традиционным современным вычислителем. Основной целью исследования явилось приближение результатов фундаментальных исследований в области квантовых технологий к их применению в прикладных задачах. Показано, как квантовые процессы могут быть перенесены в область технических измерений физических величин, используемых в сложных системах для получения информации о состоянии её нагруженных элементов. В процессе получения результатов использовались гипотетико дедуктивный метод и метод восхождения от абстрактного к конкретному в рамках системного подхода к разработке элементов технических систем. Результатом работы является описание процессов, проходящих в чувствительном элементе, воспринимающем напряжённость конструкции и созданном из модифицированного алмаза. Модифицированный алмаз с NV центром служит основой для генераторного датчика. Основной вывод исследования состоит в том, что квантовые датчики, реализованные на основе модифицированного алмаза, хорошо описываются теорией измерительных преобразователей с частотным выходом и могут быть использованы для получения данных о состоянии объекта, как функции от напряжённости элементов его конструкции.
\end{abstract}

Ключевые слова: чувствительный элемент, NV центр, квантовый датчик, частотный датчик, измерительный канал, преобразователь с частотным выходом.

\section{СПИСОК ЛИТЕРАТУРЫ}

1. Cîrstoiu C., Holmes Z., Iosue J. Variational fast forwarding for quantum simulation beyond the coherence time // NPJ Quantum Information. 2020. Vol. 6, no. 82. P. 10. DOI: https://doi.org/10.1038/s41534-020-00302-0

2. Cho, A. IBM promises 1000-qubit quantum computer-a milestone-by 2023 [Электронный pecypc] // Science. 15 September 2020. DOI: https://doi.org/10.1126/science.abe8122 (дата обращения 19.09.2020).

3. Горенштейн И.А. Гидростатические частотные датчики первичной информации. М.: Машиностроение, 1976. 182 с.

4. Arai K. Geometric phase magnetometry using a solid-state spin [Электронный ресурс] / K. Arai, J. Lee, C. Belthangady, D.R. Glenn, H. Zhang, R.L. Walsworth // Nature Communications 9, Article number: 4996. DOI: 10.1038/s41467-018-07489-z (дата обращения 08.09.2020).

5. Craik D.P.L.A., Kehayias P., Greenspon A.S. и др. A microwave-assisted spectroscopy technique for determining charge state in nitrogen-vacancy ensembles in diamond [Электронный pecypc] // arXiv.org. URL: https://arxiv.org/abs/1811.01972v1 (дата обращения 02.10.2020). 
6. Bhallamudi V., Hammel P. Nanoscale MRI [Электронный pecypc] // Nature Nanotechnology. 2015. Vol. 10. Pp. 104-106. DOI: https://doi.org/10.1038/nnano.2015.7 (дата обращения 08.10.2020).

7. Bucher D.B. Hyperpolarization-enhanced NMR spectroscopy with femtomole sensitivity using quantum defects in diamond / D.B. Bucher, D.R. Glenn, H. Park, M.D. Lukin, R.L. Walsworth // Physical Review X. DOI: 10.1103/PhysRevX.10.021053 (дата обращения 08.09.2020).

8. Casola F., van der Sar T., Yacoby A. Probing condensed matter physics with magnetometry based on nitrogen-vacancy centres in diamond [Электронный pecypc] // Nature Review Materials. 2018. Vol. 3. Article number: 17088. URL: https://www.nature.com/articles/natrevmats201788 (дата обращения 08.09.2020).

9. Teeling-Smith R.M., Jung Y.W., Scozzaro N. и др. Electron paramagnetic resonance of a single nanodiamond attached to an individual biomolecule // Biophysical Journal. 2016. Vol. 110, iss. 9. Pp. 2044-2052. DOI: https://doi.org/10.1016/j.bpj.2016.03.022

10. Schloss J.M. Simultaneous broadband vector magnetometry using solid-state spins / J.M. Schloss, J.F. Barry, M.J. Turner, R.L. Walsworth // Physical Review Applied. 2018. Vol. 10, iss. 3. Pp. 034-044. DOI: https://doi.org/10.1103/PhysRevApplied.10.034044

11. Hopper D.A., Shulevitz H.J., Bassett L.C. Spin readout techniques of the nitrogenvacancy center in diamond // Micromachines. 2018. Vol. 9, iss. 9. 437. DOI: https://doi.org/10.3390/ mi9090437 (дата обращения 08.09.2020).

12. Fernández-Acebal P., Rosolio O., Scheuer J. и др. Toward hyperpolarization of oil molecules via single nitrogen vacancy centers in diamond // Nano Lett. 2018. Vol. 18, no. 3. Pp. 18821887. DOI: https://doi.org/10.1021/acs.nanolett.7b05175

13. Jaskula J.-C. Improved quantum sensing with a single solid state spin via spin to charge conversion [Электронный pecypc] / J.-C. Jaskula, B.J. Shields, E. Bauch, M.D. Lukin, A.S. Trifonov, R.L. Walsworth // Physical Review Applied, vol. 11, iss. 6. DOI: https://doi.org/10.1103/ PhysRevApplied.11.064003 (дата обращения 08.09.2020).

14. Marseglia L., Saha K., Ajoy А. и др. Bright nanowire single photon source based on siv centers in diamond [Электронный ресурс] // Optics Express. 2018. Vol. 26, iss. 1. Pp. 80-89. DOI: https://doi.org/10.1364/OE.26.000080 (дата обращения 08.09.2020).

15. Ohtsu M. Dressed photon technology [Электронный ресурс] // Nanophotonics. 2012. Vol. 1, iss. 1. Pp. 83-97. DOI: https://doi.org/10.1515/nanoph-2011-0001 (дата обращения 08.09.2020).

16. Jia W. Ultra-broadband coplanar waveguide for optically detected magnetic resonance of nitrogen-vacancy centers in diamond [Электронный ресурс] / W. Jia, Z. Shi, X. Qin, X. Rong, J. Du // Review of Scientific Instruments. 2018. Vol. 89, iss. 6. DOI: https://doi.org/10.1063/ 1.5028335 (дата обращения 08.09.2020).

17. Wolfe C.S. Spatially resolved detection of complex ferromagnetic dynamics using optically detected nitrogen-vacancy spins [Электронный pecypc] / C.S. Wolfe, S.A. Manuilov, C.M. Purser, R. Teeling-Smith, C. Dubs, P.C. Hammel, V.P. Bhallamudi // Applied Physics Letters. 2016. Vol. 108, iss. 23. DOI: https://doi.org/10.1063/1.4953108 (дата обращения 08.09.2020).

18. Tang H., Ahmed I., Puttapirat P. и др. (2018). Investigation of multi-bunching by generating multi-order fluorescence of NV center in diamond [Электронный ресурс] // Physical Chemistry Chemical Physics. 2018. Vol. 20, iss. 8. Pp. 5721-5725. DOI: https://doi.org/10.1039/C7CP08005K (дата обращения 08.09.2020).

19. Labanowski D. Voltage-driven, local, and efficient excitation of nitrogen-vacancy centers in diamond [Электронный ресурс] / D. Labanowski, V.P. Bhallamudi, Q. Guo, C.M. Purser, B.A. McCullian // Science Advances. 2018. Vol. 4, no. 9. 6 p. DOI: 10.1126/sciadv.aat6574 (дата обращения 08.09.2020).

20. Chrostoski P., Sadeghpour H.R., Santamore D.H. Electric noise spectra of a nearsurface nitrogen-vacancy center in diamond with a protective layer [Электронный pecypc] // Physical 
Review Applied. 2018. Vol. 10, iss. 6. DOI: https://doi.org/10.1103/PhysRevApplied.10.064056 (дата обращения 08.09.2020).

21. Murai T., Makino T., Kato Н. и др. Engineering of fermi level by nin diamond junction for control of charge states of NV centers [Электронный ресурс] // Applied Physics Letters. 2018. Vol. 112, iss. 11. DOI: https://doi.org/10.1063/1.5010956 (дата обращения 08.09.2020).

22. Subedi S.D. Laser spectroscopy of highly doped NV-centers in diamond [Электронный pecypc] / S.D. Subedi, V.V. Fedorov, J. Peppers, D.V. Martyshkin, S.B. Mirov, L. Shao, M. Loncar // Proceedings SPIE, 2018. Vol. 10511. Solid State Lasers XXVII: Technology and Devices, 105112D. DOI: 10.1117/12.2290705 (дата обращения 08.09.2020).

23. Sjolander T.F. 13C-Decoupled J-coupling spectroscopy using two-dimensional nuclear magnetic resonance at zero-field [Электронный pecypc] / M.C.D. Tayer, A. Kentner, D. Budker, A. Pines // The Journal of Physical Chemistry Letters. 2017. Vol. 8, iss. 7. Pp. 1512-1516. DOI: 10.1021/acs.jpclett.7b00349 (дата обращения 08.09.2020).

24. Udvarhelyi P. Spin-strain interaction in nitrogen-vacancy centers in diamond [Электронный ресурс] / V.O. Shkolnikov, A. Gali , G. Burkard, A. Pályi // Physical Review B. 2018. Vol. 98, iss. 7. 075201. DOI: 10.1103/PhysRevB.98.075201 (дата обращения 08.09.2020).

25. Zhang M.J.H., Ku F., Casola C.H. и др. Spin-torque oscillation in a magnetic insulator probed by a single-spin sensor [Электронный pecypc] // Physical Review B. 2020. Vol. 102, iss. 2. 024404. DOI: https://doi.org/10.1103/PhysRevB.102.024404 (дата обращения 08.09.2020).

26. Barfuss A. Strong mechanical driving of a single electron spin [Электронный ресурс] / A. Barfuss, J. Teissier, E. Neu, A. Nunnenkamp, P. Maletinsky // Nature Physics. 2015. Vol. 11. Pp. 820824. DOI: 10.1038/NPHYS3411 (дата обращения 08.09.2020).

27. Delaney P., Greer J.C., Larsson J.A. Spin-polarization mechanisms of the nitrogenvacancy center in diamond [Электронный pecypc] // Nano Letters. 2010. Vol. 10, iss. 2. Pp 610-614. DOI: https://doi.org/10.1021/n1903646p (дата обращения 08.09.2020).

28. Zhu X., Saito S., Kemp А. и др. Coherent coupling of a superconducting flux qubit to an electron spin ensemble in diamond [Электронный ресурс] // Nature. 2011. Vol. 478. Pp. 221-224. DOI: https://doi.org/10.1038/nature10462 (дата обращения 08.09.2020).

29. Liu G.-Q., Pan X.-Y. Quantum information processing with nitrogen-vacancy centers in diamond [Электронный pecypc] // Chinese Physics B. 2018. Vol. 27, no. 2. DOI: https://doi.org/10.1088/1674-1056/27/2/020304 (дата обращения 08.09.2020).

30. Волков Д.И., Проскуряков С.Л. Ультразвуковой метод контроля качества режущих пластин из сверхтвердых материалов // Известия Самарского научного центра Российской академии наук. 2016. Том 18, № 1-2. С. 166-169.

31. Timoshenko S. Vibration Problems in Engineering [Электронный ресурс] // D. N.Y., Van Nostrand Company, Inc., 1937. 470 p. URL: https://archive.org/details/vibrationproblem031611mbp/ mode/2up (дата обращения 02.10.2020).

\section{СВЕДЕНИЯ ОБ АВТОРАХ}

Дианов Сергей Вячеславович, кандидат технических наук, доцент МГТУ ГА, tehnomat@ya.ru.

Новичков Вадим Михайлович, кандидат технических наук, доцент, доцент Московского авиационного института (национальный исследовательский университет), v13217@уа.ru.

$\begin{array}{llll}\text { Поступила в редакцию } & 02.10 .2020 & \text { Received } & 02.10 .2020 \\ \text { Принята в печать } & 26.11 .2020 & \text { Accepted for publication } & 26.11 .2020\end{array}$

